recommend doing that - will rack up legal and federal processing fees and other expenses of up to US $\$ 8,000$.

There are other caveats. One is that greencard renewal, although usually routine, requires the holder to be free of certain criminal convictions. Some missteps, such as overstaying a previous visa, may render the applicant ineligible. Another sticking point is that trips out of the country beyond 179 days require USCIS re-entry permits, which provide for absences of up to two years. Scientists who travel outside of the country on collaborations or fieldwork for more than six months at a time should be aware that the USCIS might interpret those trips as abandonment of their US residence and move to deport them.

Opinions vary on the best time for an earlycareer researcher to pursue a green card. Some immigration experts say that it can take as long as eight years after a researcher's US career launch, depending on the quality of their publication and citation records.

With so much riding on the card, a rush to apply can create anxiety. Hou-Sung Jung, a research assistant professor of plant biology at Dartmouth College in Hanover, New Hampshire, experienced this first-hand. The South Korea native spent seven years as a postdoc, mostly on an $\mathrm{H}-1 \mathrm{~B}$ visa. Busy with his research, publications and a new marriage, he forgot about the visa's expiry date. He was able to assemble the documentation and materials for a green-card application within two months and received the card with a month to spare. "I was lucky," says Jung.

Some immigra-

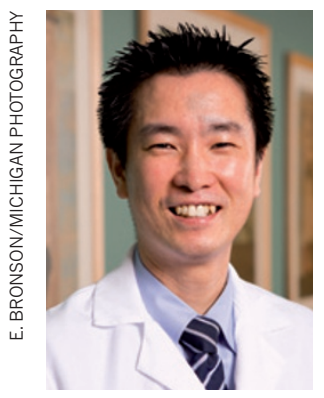
tion experts counsel that a researcher arriving in the United States on a temporary visa of any type should immediately start educating themselves on the process and details of acquiring the green card, even if they

"Getting the right information was a big struggle in the very beginning." Sadakatsu lkeda don't expect to want one. "If you leave things too late, you may find yourself in a position where you're running out of options," says Delaney, who, as a native of Northern Ireland, has gone through the process himself.

Applicants may receive conflicting or inaccurate information from employers that steers them down the wrong path. "At the green-card centre at one university, the information on the process was so confusing," says Sadakatsu Ikeda, a native of Japan who is a clinical fellow
TOP TIPS

\section{Gathering the evidence}

- Start amassing necessary documentation as early as possible: birth certificate, academic degrees, proof of scientific-society and association memberships, invited conference presentations, book chapters, copies of or links to media interviews and their dates, awards and dates, published manuscripts, citation indexes, journal impact factors. - Network at every chance you get: you need to create an association of highlevel colleagues outside your institution with whom you have not collaborated, including, for example, contacts from conferences or talks. They will be your sources for up to five letters of recommendation, which will be more influential than those from institutional or collaborative colleagues.

- Write the letters yourself, focusing on different accomplishments for each that illustrate how you fit into the category under which you're applying. Send to the appropriate recipient with a stamped, self-addressed envelope and provide a deadline. K.K.

in haematology and oncology at the University of Michigan in Ann Arbor. "Different people told me different things." Ultimately, he decided to pursue the self-sponsored route for the freedom to move to different employers and to control the process himself.

Shortly after starting a molecular biology and genetics postdoc at Harvard Medical School in Boston, Massachusetts, Ikeda hired an attorney who showed him how to apply under the National Interest Waiver subgroup and recommended that Ikeda work on publishing citable papers, building an extensive network of contacts and getting his name widely known in his field. By the time Ikeda began to pursue the application seven years later, after a three-year residency, he was first or second author on a number of papers in high-impact journals, had amassed a robust contacts network and was well known in cancer research. He had no trouble getting five letters of recommendation, and received his green card without any hassle six months later.

"Getting the right information was a big struggle in the very beginning, and building this network and my reputation - that was the biggest obstacle," says Ikeda. "But in the end, I was successful because I had a good roadmap."

Karen Kaplan is assistant Careers editor at Nature.

\section{PARTNERSHIPS}

\section{UK recruitment drive}

Recruitment of academic researchers is under way at Queen's University Belfast (QUB), the University of Manchester and University College London (UCL) in connection with around $£ 1$ billion (US\$1.6 billion) in awards from the UK government's Research Partnership Investment Fund and associated philanthropic donations. QUB will use its $£ 32$-million share to help hire 500 researchers and clinicians for its healthsciences institute, which includes a new research centre for eye disease and diabetes slated for completion in 2016. Manchester will hire about 20 senior academics in 2013 for cancer research, and UCL expects to create more posts at a new centre for rare paediatric diseases scheduled to open in 2018.

\section{EDUCATION}

\section{Teachers without PhDs}

British postgraduate students might often be better qualified than their lecturers, according to a study, Academic Staff in UK Higher Education Institutions, released on 1 November. The report finds that just over half of the full-time academic staff across all disciplines and institutions have doctoral degrees. Author Malcolm Tight at Lancaster University, UK, warns that the results reflect poorly on the quality of postgraduate education at some UK universities. He argues that universities have focused on diversifying their student base at the expense of developing the quality of their faculty. "It's certainly possible that a doctoral student might have more knowledge of a discipline than her or his professor," Tight says.

\section{POSTGRADUATES}

\section{International enrolment}

First-time enrolment of international graduate students in the United States rose $8 \%$ for 2011-12 across all academic fields, matching the previous year's increase, according to the latest survey by the US Council of Graduate Schools in Washington DC. Gains in the sciences alone were more modest, with life sciences up $1 \%$ and physical sciences $4 \%$. Business and engineering led all fields with gains of $15 \%$ and $12 \%$ respectively. China continues to send increasing numbers of graduate students to the US; enrolments were up $22 \%$ from the previous year, the seventh consecutive year of growth. 